See Article page 176

\section{Commentary: Game, set, patch?}

\author{
Hellmuth R. Muller Moran, MD, and \\ Michael H. Yamashita, MDCM, MPH, FRCSC
}

Takayasu arteritis, although predominantly a large-vessel disease, may uncommonly involve the coronary circulation. In such cases, ostial disease is often observed, ${ }^{1}$ although all segments of a coronary artery may be at risk. ${ }^{2,3}$ Affected individuals typically present between ages 25 and 30 years $^{1}$; therefore, when considering treatment options it is of utmost importance to ensure that any chosen strategy will produce a durable long-term result.

Oishi and colleagues ${ }^{4}$ present the results of a case at 15 years following patch angioplasty of both coronary artery ostia using autologous superficial femoral artery (SFA). At 15-year follow-up, both repaired ostia were widely patent with no evidence of aneurysmal disease or calcification. Other treatment options for this pathology have previously been described, including medical therapy; percutaneous coronary intervention; coronary artery bypass grafting; endarterectomy; and patch angioplasty using saphenous vein, bovine, or autologous pericardium. There is evidence to suggest that results after coronary artery bypass grafting are generally superior to percutaneous coronary intervention ${ }^{2}$ and may further synergize with medical therapy ${ }^{3}$ depending on the level of disease activity. However, this level of evidence is not available for patch angioplasty methods.

The obvious strength of this report is the excellent longterm result seen at 15 years following patch angioplasty. From it we can conclude that, under the right circumstances, patch angioplasty using the SFA may potentially

\footnotetext{
From the Division of Cardiac Surgery, Department of Surgery, Max Rady College of Medicine, University of Manitoba, Winnipeg, Manitoba, Canada, and Cardiac Sciences Program, St Boniface Hospital, Winnipeg, Manitoba, Canada.

Disclosures: The authors reported no conflicts of interest.

The Journal policy requires editors and reviewers to disclose conflicts of interest and to decline handling or reviewing manuscripts for which they may have a conflict of interest. The editors and reviewers of this article have no conflicts of interest.

Received for publication April 8, 2020; revisions received April 8, 2020; accepted for publication April 10, 2020; available ahead of print May 1, 2020.

Address for reprints: Michael H. Yamashita, MDCM, MPH, FRCSC, St Boniface Hospital, Y3519-369 Tache Ave, Winnipeg, MB, Canada R2H 2A6 (E-mail: myamashita@sbgh.mb.ca).

JTCVS Techniques 2020;3:181-2

2666-2507

Copyright (C) 2020 The Authors. Published by Elsevier Inc. on behalf of The American Association for Thoracic Surgery. This is an open access article under the CC BY-NCND license (http://creativecommons.org/licenses/by-nc-nd/4.0/).

https://doi.org/10.1016/j.xjtc.2020.04.011
}

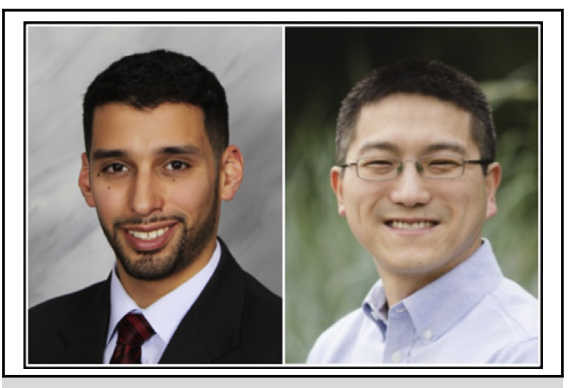

Hellmuth R. Muller Moran, MD, and Michael $\mathbf{H}$. Yamashita, MDCM, MPH, FRCSC

\section{CENTRAL MESSAGE}

Coronary ostial arterial patch angioplasty may result in longterm, disease-free survival from Takayasu arteritis. Its effectiveness compared with other techniques remains to be determined.

result in long-term, disease-free patency. However, we must also acknowledge its limitations as a single-center, single-patient case report. In particular, the described patient had no documented evidence of systemic or regional inflammation during follow-up despite the absence of anti-inflammatory or immunosuppressive treatments, placing her in the cohort of patients with quiescent disease and in whom surgical results are known to be superior. ${ }^{1}$ It is therefore unclear how the arterial patch angioplasty technique would fare over the long term in individuals with higher levels of disease activity because there would presumably be systemic arterial involvement in such cases. Indeed, this is among the purported benefits of saphenous vein or pericardium over arterial patch angioplasty. Moreover, as novel therapeutic agents continue to modify the landscape of this disease,,$^{5}$ their effect on traditional surgical techniques and implants will need to be closely monitored.

Nonetheless, the result seen here is admirable and the authors are to be commended for their excellent work. If enough evidence accumulates to suggest that the results of coronary ostial patch angioplasty using the SFA are superior to other techniques in multiple patients at multiple centers, we may someday be able to confidently proclaim "Game, set, patch!" and proceed with the aforementioned treatment for affected individuals. Until such time, we 
encourage surgeons to continue using the techniques that they are familiar with and that are likely to produce the most durable long-term results in their hands.

\section{References}

1. Kim ESH, Beckman J. Takayasu arteritis: challenges in diagnosis and management. Heart. 2018;104:558-65.

2. Wang H, Zhang Y, Shen Z, Fang L, Liu Z, Zhang S. Comparing the effects of different management strategies on long-term outcomes for significant coronary stenosis in patients with Takayasu arteritis. Int J Cardiol. 2020; 306:1-7.

3. Yang Y, Tian T, Yang K, Zhang Y, Meng X, Fan P, et al. Outcomes of percutaneous coronary intervention and coronary artery bypass grafting in patients with Takayasu arteritis. Int J Cardiol. 2017;241:64-9.

4. Oishi K, Arai H, Yoshida T. Coronary ostial plasty using femoral artery patch in Takayasu aortitis: a 15-year follow-up study. J Thorac Cardiovasc Surg Tech. 2020;3:176-8.

5. Pan L, Du J, Liu J, Liao H, Liu X, Guo X, et al. Tocilizumab treatment effectively improves coronary artery involvement in patients with Takayasu arteritis. Clin Rheumatol. March 6, 2020 [Epub ahead of print]. 